This is an Accepted Manuscript of an article published by Taylor \& Francis in Information, Communication and Society on 29 Nov 2018, available online: http://www.tandfonline.com/10.1080/1369118X.2018.1548632. 
If citing this document please use:

Darcy, S., Yerbury, H. and Maxwell, H. (2019), 'Disability citizenship and digital capital: the case of engagement with a social enterprise telco', Information, Communication and Society, vol. 22, no.4, pp. 538-553.

\section{Disability citizenship and digital capital: the case of engagement with a}

\section{social enterprise telco}

Simon Darcy, University of Technology Sydney

Hilary Yerbury, University of Technology Sydney

Hazel Maxwell, University of Tasmania

This paper uses as its base a key initiative involving a not-for-profit organisation (NPO), government start-up funding and a social enterprise which evolved through three phases. The purpose of the initiative was the development of a smart phone technology platform for people with disability. The paper's purpose is to answer questions about the ways in which the mobile technology, seen here as assistive technologies, supported the development of disability citizenship and active citizenship. Data were collected through in-depth interviews conducted at three points in the 13-week programme during which participants with disability received customised support for their phone and training in its use, at no cost. Fifteen participants volunteered to take part in the research project, along with their significant other and service provider. Key themes were identified in the preliminary analysis. Exploring these using Ragnedda's ([2017]. The third digital divide: A Weberian approach to digital inequalities. Abingdon: Routledge) three levels of digital divide, and Wilson's ([2006]. The information revolution and developing countries. Cambridge, MA: MIT Press) categories of access allowed a series of philosophical, ethical and human services management questions to emerge, challenging the optimism with which the digital economy is presented as a solution to issues of inequality. Although the mobile technologies were very successful as assistive technologies for some participants, the findings reinforced the potential for such technologies to further entrench aspects of social exclusion. They also identified ways in which the shift in the role of the NPO to social 
entrepreneurship, and its relationships with government and private enterprise, had the potential to undermine the exercise of disability citizenship by turning participants into consumers.

\section{Introduction}

Smart phone technologies are so much part of everyday life that their potential as assistive technologies for people with disability has often been overlooked. Studies showed that access to and use of mobile technologies have been difficult for people living with disability for a variety of reasons, including cost (ITU and G3ict 2012; Macdonald \& Clayton, 2012), the attitudes held by allied health workers and the community that such technologies could not be used by people with disability and failure to include people with disability in the design and development of these technologies (Scherer 2002). However, the adoption of these technologies can give people with disability access to aspects of life that the majority of the community regard as essential (Cumming, Strnadova, Knox \& Parmenter, 2014). The Australian Communication and Media Authority (2013) reported that developers, regulators and service providers were interested in the potential of mobile technologies to support assistive technologies, especially through messaging, GPS, way-finding and location, speech, landmark identification and other applications. Each of these technologies has the potential to overcome activity limitations which can restrict social participation (Australian Bureau of Statistics, 2011).

This paper uses as its base a key initiative involving a not-for profit organisation (NPO), government start-up funding and the development of a social enterprise. The social enterprise licensed capacity from a mainstream telecommunications company and the project involved the development of a smart phone technology platform and the introduction of the platform with a test group of people living with disability. This social enterprise was directly connected to the not-for-profit in the first and second stages of its operation before becoming a for-profit social enterprise proprietary limited company in the third stage of its operation (please see figure 1 and a fuller explanation in the study section). The research involved investigating the effect of the mobile phone technology platform on the education, training, and support of participants with disability in the digital economy (Ellis \& Kent, 2011; Darcy, 
Green and Maxwell, 2016; Darcy, Maxwell and Green, 2017; Goggin \& Newell, 2003). The data from the study have been used here to answer the question 'What are the implications of the use of mobile technologies in facilitating disability citizenship in a social entrepreneurial telco start- up situation?'

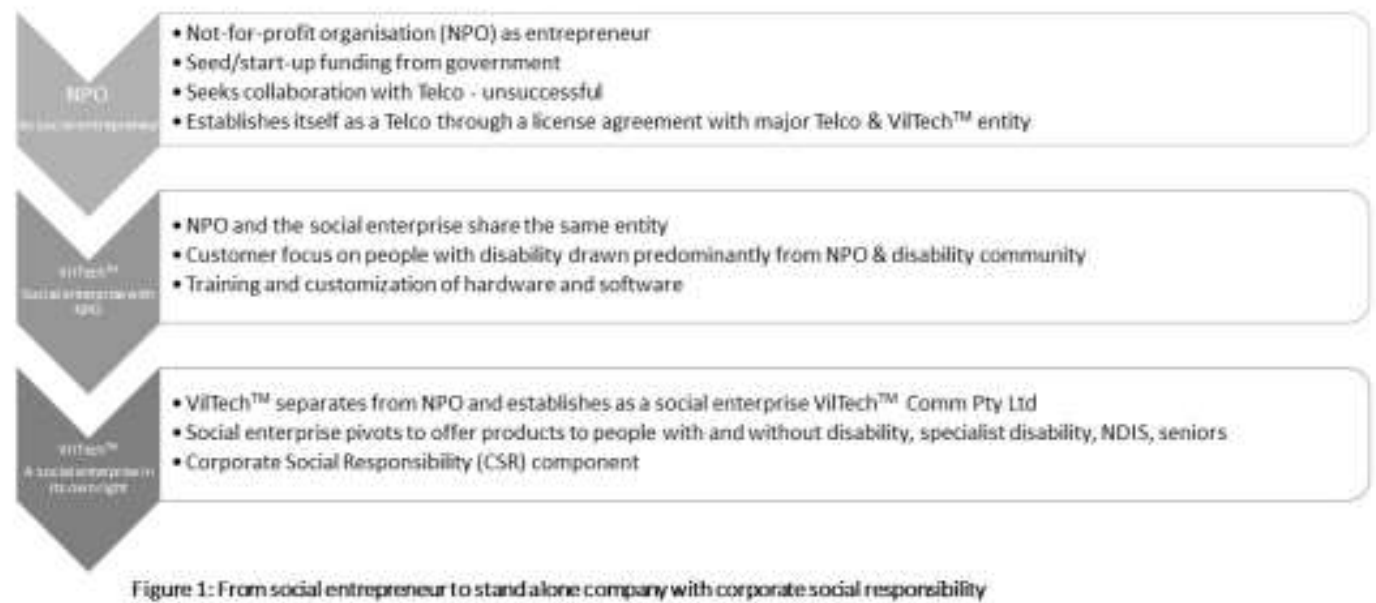

Such a study is significant for several reasons. Firstly, it facilitates a consideration of the use of ICTs in social inclusion, identifying, from the perspective of those with a disability and their significant other, aspects of disability citizenship and of active citizenship; secondly, it explores the informationmediated relationship between the participants in the project and the newly established Telco, extending this beyond the experiential learning approach of the original project and the previously published papers (Darcy et al., 2016, 2017.); thirdly, it offers insight into the nexus between a change in social policy with the introduction of the NDIS, a change in the role of the NPO, Village Networks, through the development of the social enterprise, and those clients of Village Networks who sought to take up the opportunities offered through engagement in the project.

The research project was situated within social models of disability (Barnes, Mercer, \& Shakespeare, 2010; Oliver, 1996) espoused by the United Nations Convention on the Rights of Persons with Disabilities (United Nations, 2006). The social model of disability breaks 'the linear causal link 
between impairment and the state of being disabled' (Reindal, 2010, p. 126); which is the underlying principle that the medical model is based on. Its socio-political stance detaches impairment, the physical condition or restriction, from the individual understanding of living with a disability (Vehmas \& Mäkelä, 2009), focussing on the lived experience of disability and the disabling environmental and attitudinal barriers (Oliver, 1996) and accentuating the fact that people with disability have a right to social participation. The social model identifies both environmental and attitudinal barriers to participation in society. However, like other social constructionist or critical theories, the social model of disability searches for transformational results rather than just distinguishing obstacles to participation in the wider community (Swain, French \& Cameron, 2003).

This adoption of the social model of disability was pivotal in considering the effect of the technology on participation in society, and thus on the disability citizenship of those involved. This led to a consideration of its effects on engagement in the digital economy and on the exercise of active citizenship through the lens of Ragnedda's (2017) typology of the digital divide and Wilson's (2006) categorisation of access to services. This approach goes beyond identification of barriers to social participation, seeking the transformational outcomes of interventions.

The study acknowledged the significant influence that assistive technology can have for people with a disability accessing the community from mobility, sensory and cognitive perspectives and considered the smart phone technology developed through this initiative as, potentially, an assistive technology. Friesen, Theodoros, and Russell (2015) have proposed that all assistive technology is really about 'usability-for-one'. This idea combines well with Thomas' (2004) approach to disability which indicates that there should be room for an individual's 'impairment effects' and that enabling environments should be developed based on the needs of each person with a disability. On the other hand, an emphasis on usability and accommodations for disability is limiting, even when it allows space for consideration of the context of the individual. Such an emphasis can marginalise other factors affecting the successful integration of assistive technology into the life of an individual with disability. These include skills and expertise, digital literacy, economic capacity, as well as social and cultural engagement. 
Coinciding with the research (2013-2014), the policy context for service provision to people with disability in Australia was undergoing a profound change, with the launch of the National Disability Insurance Scheme (NDIS) in Australia (Commonwealth Government, 2013). For the previous thirty years, governments at State and Federal level had provided block funding to organisations engaged in providing services to people with disability. Under this policy, decision-making and control over the services was the responsibility of the service providing organisations. The NDIS is a no-fault insurance cover for Australians with severe or profound disability (Baker, 2012), providing the funds to the person with disability, in theory, giving the individual control over the decision on which services they need and where to purchase them from and over the management of the budget (Lord \& Hutchinson 2003).

\section{From digital divide to digital inequality}

At one level, this study is about the concept of the digital divide. This should not be seen as that gap created by the dichotomy of access and lack of access to information technologies, but as something more complex, since the acceptance of a dichotomous digital divide can mislead discussion (DiMaggio and Hargittai 2001). Warschauer (2003) argues that the original concept of the binary divide has long since been outdated, although it persists. Scholars including van Dijk (1999) and Wilson (2006) have argued that, for the concept of access to be adequately understood, it is not a matter of using near synonyms such as accessibility and availability to add new dimensions to a discussion, but rather of using adjectives to add new dimensions to the concept. In an early attempt to broaden the concept of access, van Dijk (1999) took the individual as her focus and identified four types of access, which she labelled mental access, material access, usage access and skills access. Inherent in this approach is the assumption that each type of access can encompass a gap or lack of access. Wilson (2006) drew on Dervin's (1973) hierarchy of accessibility, with its five levels, ranging from intellectual accessibility, psychological accessibility and physical accessibility at the level of the individual to institutional and societal accessibility at a broader level. He takes the Internet as his focus and brings together societal, economic and technical considerations with personal factors, in a typology that includes financial access, cognitive access, production access, design access, content 
access, institutional access and political access. The notion of gap or lack, however, is still inherent in this model.

Ragnedda (2017) proposes a different approach to understanding the concept of digital divide, which is more relevant to the approach underlying this study, and that is that digital divide is concerned with inequalities. He identifies three levels of digital divide, the first concerned with the dichotomies of access, the second with inequalities in digital skills and digital capital and the third with the social and cultural benefits of using digital technologies. He argues that digital inequalities exacerbate social inequalities and thus the digital divide is a social problem. Following van Dijk, (2005), Ragnedda (2017, p. 18) suggests that this may be the case because these digital inequalities can 'limit or enhance citizens' social, economic, political, personal and cultural capital' as well as hindering their access to information and their abilities to participate in society.

These digital inequalities, 'tend to reinforce pre-existing differences in society' (Ragnedda 2017, p. 52) and thus cannot be understood from a technologically determinist position. Those already at risk of being marginalised because of age, education level, ethnicity, disability and so on are likely to find the inequalities arising from this marginalisation more firmly entrenched through the digital divide and related digital inequalities (Gonzales, 2016; Khorshed \& Sophia, 2015).

In this context of marginalisation, particularly relevant to an analysis of the findings of this study are Ragnedda's (2017) second and third levels of digital divide. He defines digital capital, as 'the set of expertise, experience, skills, knowledge, digital literacy, ICTs access, based on and which can be converted into other types of capitals (economic, social, cultural, personal and political' (2017, p. 76), thus linking the digital realm and all aspects of life . Four elements are essential to digital capital: digital literacy, literacy, confidence and abilities and language skills. Inequalities at the second levelin digital capital and digital skills - inevitably lead to marginalisation in a wide range of social and cultural activities, including 'job searching, online shopping, entrepreneurship, access to healthcare, consumer lifestyles, political engagement, socialising, learning, leisure, cybersecurity, housing, tax and relationships with bureaucracy' (2017, p. 56) 


\section{Social citizenship and active citizenship}

Marshall's concept of social citizenship, which included the right 'to live the life of a civilized being according to the standards prevailing in society' (Marshall 1965, p.78), is the forerunner of both disability citizenship and active citizenship. This concept has not been without its critics, as Buckmaster and Thomas (2009) point out, but in spite of this, it has been highly influential in shaping understandings of social inclusion in Australian social policy. A key aspect of Marshall's approach to social citizenship is that it is concerned with the resources necessary for membership and participation in society.

In spite of the criticisms levelled at it, Wilson's (2006) approach to access is useful as an analytical tool in this study because of its broad societal orientation. Ragnedda's (2017) approach to conceptualisation of the digital divide adds value because it allows a nuanced interpretation of the interventions of the participatory action research. Each will be used to shed light on the implications of the study for the exercise of active citizenship by people with disability.

\section{The Study and its context}

This paper is part of a broader study which explored the introduction of a new mobile technology to people living with a disability with significant support needs and explored the use of this mobile technology through the insights of the organisation information systems, staff, users, significant others and support workers (Darcy et al., 2016, 2017). It is important to understand both the development of the social enterprise and the underlying digital disruption for improving people with disabilities lives. The following two sections outline these important contributions to the study.

Evolution of a social enterprise As Dacin, Dacin \& Matear (2010) identify there have been multiple definitions of social entrepreneur and social enterprise that have similar underlying characteristics. Using an early definition of social entrepreneur, 'The use of entrepreneurial behavior for social ends rather than for profit objectives, or alternatively, that the profits generated from market activities are used for the benefit of a specific disadvantaged group' (Leadbetter, 1997), the definition captures 
three broad stages of development of a social enterprise by an NPO before the enterprise was established as a standalone for-profit social enterprise. The stages are outlined in Figure 1.

To expand upon the definition above and Figure 1 showing the stages of operation, we will briefly describe the development of the social enterprise that occurred between 2011 and 2015. The social enterprise involved the provision of the mobile technology and its customisation for individual users, training in its use and access to a 24/7 call centre. The technology, known as VilTech ${ }^{\mathrm{TM}}$, was developed by Village Networks, a pseudonym for the non-profit organisation. Village Networks, within its established operations as a disability service provider and advocacy organisation, effectively became a social entrepreneur after conceiving an ambitious project to provide a telecommunications, mobile smart phone hardware and software solution for people with disability with high support needs who were its clients and in the disability community more broadly.

In doing so, the NPO could be described as providing a social constructionist approach to social enterprise development, where they saw a social need for goods and services for its clients, and the disability community more broadly, not previously addressed by businesses, government or other NPOs (Zahra, Gedajlovic, Neubaum, \& Shulmanall, 2009). In this case it involved people with disability with high support needs whom Village Networks had a history of servicing in other disability service areas. These people predominantly had intellectual/cognitive disability, but often with complex secondary disability involving mobility, vision, hearing, mental health and other disability. Quite simply these people had been marginalised and as consumers not considered worth pursuing by commercial interests due to a lack of market understanding and other factors; further, government did not regard these goods and services as an area where they should intervene in the market. VilTech ${ }^{\mathrm{TM}}$ was established as a conceptual identity in 2011 but continued to operate within the NPO as a business enterprise without separation from the NPO's other operations. After the initial government start-up investment was depleted during the establishment stage of the social enterprise, the business model was switched to a fee-for-service where users were charged for the hardware and customised communication packages (see Dawans, Alter, \& Miller (2009) for a fuller explanation of social enterprise operating models). In 2015, after the initial research was complete, the social 
enterprise was bought out by VilTech ${ }^{\mathrm{TM}}$ founders from the NPO, Village Networks, and incorporated as a proprietary limited company. The new entity, while run for profit, identifies itself as a social enterprise using the profit generated by selling mobile phone packages to all sections of the community to invest back into the company to assist people with disability to use mobile telecommunications in leading independent, dignified and more equitable lives.

\section{The program and data collection}

A 13-week program was delivered to people living with a disability in Sydney, regional NSW and Tasmania, introduced by service providers and families. These people had a variety of different disability and support needs. Each individual in the program was given a mobile phone, case, charger and lanyard, and each phone was connected to a mobile phone plan whose cost was covered by Village Networks. They each participated in two familiarisation sessions in which the technology was introduced and personalised to ensure maximum effectiveness for every individual. Every week during the program, the call centre phoned each person at random intervals to familiarise them with the process of answering calls on their phone. Furthermore, each day, each individual was also asked to phone the call centre. Participation in this program was at no cost to the individual.

Participants for the study were recruited as volunteers from those engaged in the program. Fifteen participants responded to the call for volunteers, eight males and seven females; ten participants had an intellectual disability (two of whom also had physical disability and three also had speech disability), four participants had a physical disability (including two with speech disability) and one participant had a cognitive impairment due to a brain injury. Approval from the University's Human Research Ethics Committee guaranteed that people with disability with low to very high support needs (World Health Organisation, 2001) were exposed to minimal risk and that systems were in place to support the person with disability and their significant other; this approval also emphasised the independence of the researchers. To gain a meaningful understanding of the participant's engagement in the project, three sets of in-depth interviews were planned with participants, their significant other and their support manager. 
Interviews took place between March 2013 and January 2014. The first interview, in most instances, was held before the start of the program. The second interview, took place after six weeks and the third at the end of the program. The use of semi-structured interviews allowed a kind of conversation to develop, with the interviewer being mindful of the individuals involved and their specific communication and support needs. The interview guide included questions about the participant's current access to the community, specifically in relation to employment, medical services, leisure, shopping, banking, and socialising with family and friends. Supplementary questions were used to establish current levels of support in terms of support hours, associated support activities, such as classes and individual training sessions, and support devices, such as prompt cards, signs and reminder devices. Questions identified current use of ICTs, for example, use of computers, phones and tablets, the purpose of this use and constraints on this use. Prompts on the purpose of use of ICTs included personal management, leisure and contacting friends and family; prompts on usage constraints included environmental, physical, literacy, numeracy, sequencing, memory, social knowledge, skills and reading cues.

The interviews were recorded, transcribed and then spot-checked for accuracy. Where possible and appropriate, transcripts were returned to interviewees for checking. After transcription and checking the data were analysed using NVivo version 9 software. After the initial filtering and categorisation, the analysis involved constant comparison of pre-and post-interviews (Glaser \& Strauss, 1967). Once the themes had been identified, for this study, a priori codes based on the models of Wilson (2006) and Ragnedda (2017) were applied.

\section{Findings and discussion}

A series of philosophical, ethical and human services management questions emerged from the analysis, challenging the optimism with which the digital economy is presented as a solution to issues of inequality. It soon became apparent that while the focus was on the individuals themselves (micro level), there were significant issues to address at the multiple organisational level (meso level) with potential conflicts between the role of the not-for-profit and the consequences of setting up a social 
enterprise, the expectations of the government seed funder and the commercial arrangements established with the telecommunication company and issues also arising at the level of government policy (macro level).

\section{Equalisation across the digital divide?}

Wilson's (2006) typology of access provides a useful checklist to identify how the project attempted to engage people with disability in the digital economy. The project's relationship between the NPO, the government department and the commercial telecommunications company (institutional access) meants that the mobile phone technology platform was provided at no cost to participants, with the cost of calls covered by the NPO for the duration of the pilot project (financial access). Participants received training and on-going support to enable them to achieve cognitive access. Design access was enhanced for most participants, through a process of 'soft' or 'hard' customisation; this was critical in enabling participants to use the mobile phone. The use of apps, for example a voice-activated travel app which enabled a participant with speech impairment to buy train tickets, is an example of the provision of content access. The project was set up to provide a direct relationship between the participants and their carers, a call centre and the NPO, which through the social enterprise provided customisation of the technology and training in its use (political access). Finally, participants were able to create their own content (production access), whether this involved taking photos, writing texts and narratives or engaging in conversations. From this perspective, the results of the study indicate that, at a superficial level, the project helped to foster equality across the digital divide.

An analysis of the project's implementation, focussing on Ragnedda's (2017) levels two and three of the digital divide, presents a more nuanced picture of the ways in which inequalities were overcome or further entrenched through the introduction of the mobile phones. The project itself, by providing access to an assistive technology, the mobile phone with particular customised features, and training and support in its use, already provided a more level playing field for one participant:

[The participant] had been asking for a mobile phone for a few years and it was just on the backburner because we couldn't figure out how to do it, because we couldn't 
figure out how you could use a mobile if you couldn't talk into it. (Family member of participant \# 10)

It was clear from the interviews that the development of 'digital capital' was at the heart of this project. Participants, carers and staff all discussed the development of knowledge and skills:

She actually taught herself how to do a video. Like three or four days after she had it, (she) came home and she had videoed the neighbourhood, 'This is where I live and across the road is the school and this is the front of the house...' She'd done a little video like that. So she's worked out how to do the video (Family member of participant \# 5).

Furthermore the Help Centre and its staff were fundamental to the development of digital capital, through skills development, customisation of the technology and on-going help and support. A staff member at Village Networks explained 'he has a specific training plan in terms of just practising ... his greetings, his transport, his ... games' (Staff member \#2). Staff at the Help Centre noted that some problems with using the phone could be as simple as a participant understanding the need to charge the phone each night, whereas others were related to the physical capacity of a participant to hold or use the phone. For example, one stated that 'he's got like a hand tremor and ... sometimes he can miss-hit the buttons and things like that, which was sort of a bit slow and laborious' (Staff member \# 3). The new knowledge and skills, 'human capital', was frequently turned into 'social capital' through communication with family members and socialisation with friends or into the 'cultural capital' of being able to choose music to dance to. To summarise a participant stated that 'I use it when I'm phoning my social group' (Participant \# 2).

Participants developed 'personal capital', feeling empowered and gaining a measure of autonomy and confidence they had not had before. 'Number one, it's the ability to have a voice that comes through, so it's actually the ability to just say I would like to buy a ticket to Parramatta station' (Participant \# 8). Additionally, one participant was able to create 'economic capital'; enhancing her business operations through the use of the Call Centre and their staff. She explained that she used her mobile 
device 'when I need to renew hosting packages for my web design customers' (Participant \# 6). The action research approach facilitated the development of 'political capital', as participants and others could discuss requirements for additional customisation of additional training.

This approach to the digital divide allows for consideration of disability citizenship (Darcy et al., 2016; Harris, 2010). There are clear examples of increased social participation and individual autonomy, including increased freedom to travel without the worry of being lost because of the GPS function of the phones. Further, the training and customisation gave some participants the ability to follow an individual approach to use of the phone, exploring the capacities of the phone, as any person might. One service provider noted that using the phone, a participant and his friends 'were able to bond and just kick back as normal blokes' (Staff \#1). The call centre, operating 24/7, became a multiplier of opportunities, as staff there helped individuals remove barriers to achieving their goals and do things they had previously been unable to do. However, by the same token, the inability to master physical skills was a cause of frustration and exacerbated inequalities. Being unable to 'swipe right' or to press the buttons with the right amount of force or to plug in the relatively small charger connection meant that a participant found it difficult to develop an appropriate level of digital capital and therefore was excluded, at least temporarily, from the possibility of creating other forms of capital in the digital realm.

\section{Never a level playing field}

Enthusiasm for using the technology differed across the participants and also among their significant others (Darcy et al. 2016). Some participants $(n=6)$ were identified as 'evangelists', benefitting from the mobile phone technology because of their enthusiasm and their ability to integrate it into their everyday lives. Common refrains included 'she just loves having it and she's got it with her all the time' (Family member of participant \#2). A further four were identified as 'embarkers', who did not necessarily express enthusiasm for the technology and did not use it to its full potential. However, these people did see possibilities for increased usage, often following additional training or other 
support. A family member explained 'more individual and ongoing training and support would have been beneficial in using the phone' (Family member of participant \# 10).

Five participants were identified as 'discontinuers', either lacking interest in continuing to use the technology, because of barriers to use or because the new phone and its capacity was no improvement on the phone the participant currently used.

My [old] one is just the little phone with everything in one spot. So even though the phone worked really well, I just prefer it all in one spot where I can easily access everything (Participant \# 12).

It is also noteworthy that all those who discontinued their involvement in the project had an intellectual disability. One might argue here, as Ragnedda (2017) does, that for these participants, existing social inequalities were reinforced by the problems of using the technology. Similarly, some participants with high support needs found that the additional support they needed was not forthcoming because it created an insurmountable level of tension around conflicting priorities in a household.

\section{Technology and the human}

A question arises around what level of training and support participants would need to make effective use of the technology. To a significant extent, however, this is not just a question about the content of training or the duration of training, in spite of comments such as the following: 'If maybe, there'd been someone who could have spent quite a bit of time with you to actually go through and practise with the buttons that would have been something that would have been useful' (Participant \# 11). The program was about the use of the mobile telephone as an assistive technology. The identified range of desirable outcomes for a participant was to be reached through training of the participant and the significant other (so that it might be argued that the content of training was fixed) and the customisation of the technology which sometimes had to be a case of trial and error.

Consequently, in any discussion of human services management issues, the technology itself cannot be overlooked as an actor in the development of active citizenship. On the one hand, the introduction 
of speech which enabled a participant to buy train tickets, or the addition of a photo on a button allowing a participant to know she was calling her father for help and support were positive examples of the modification of technology. On the other hand, knowing that a button must be pressed or swiped was, for some participants, secondary to the ability to press or swipe appropriately. Modifications to the handsets could be seen as ways to substitute technology for human interventions. The support provided by the Call centre, whose staff were available $24 / 7$ to participants, suggested that there were times when the staff took over the role of technology, and acted on behalf of participants, at their request making phone calls for them. The distinction here is potentially a fine one: doing something the technology could not do or doing something the participant could not do. This raises questions both about training of the participants and modification of the technology.

\section{Empowerment and its problems}

Ethical questions arose around the conflict between empowerment of the participants to use the smart phone technologies to enhance their active citizenship and adherence to societal conventions, as noted by the significant others and the service providers. Marshall's concept of social citizenship (1965) includes a sense of adherence to social conventions. Some participants with intellectual disability were able to use the telephone to initiate communication with others for the first time. While they were able to develop the technical skills necessary to operate the phone, they did not yet have the social skills to understand that there are conventions on when or how often one can make telephone calls. A parent articulated that 'although the SMS function was supposed to have been removed, she has been able to access it, and one day sent her mother 30+ messages' (Family member of participant \# 1). This was a cause of inconvenience and frustration to some of those receiving calls at inappropriate times or frequencies and to some extent a cause of embarrassment for the significant others. These participants were empowered, able to make decisions and do things, including communicating with others, which they had not been able to do before; they were taking the opportunity to enact aspects of active citizenship. 
However, active citizenship is about more than 'doing things'; it includes understanding the context in which actions take place. Thus, significant others were faced with a twofold ethical dilemma: whether to support these examples of autonomous action and attempt to develop the inadequate understanding of the social conventions, so that the person was empowered as others are; or to show displeasure or annoyance at the inappropriate behaviour and set rules around the use of the phone for calling certain people. Those on the receiving end of the inappropriate calls, especially where they were part of the social network of the participant, were faced with a similar dilemma.

\section{Considering the meso and macro levels}

The focus in the discussion thus far has been at the micro level, focussing on the individual participant, their significant other and their interactions with the technology and the services provided in this project in their everyday lives. To move to a consideration of the meso and macro levels, it will be useful to return to Dervin's hierarchy of accessibility. Intellectual accessibility, psychological accessibility and physical accessibility have already been touched on in the consideration of Ragnedda's (2017) levels of the digital divide.

The other two levels of the hierarchy, institutional accessibility and societal accessibility, can be applied at the meso level and the macro level as institutional accessibility is concerned with the existence of organisations able and willing to take an active part in providing the resources needed by individuals and societal accessibility assumes that the society itself recognises the issues and problems faced by individuals and makes available within the societal system the resources necessary to meet the needs of the individuals.

The meso level in this study is complex, because of the shift in roles of organisations over time. Originally, it comprised organisations of three types, the government, the NPO, which received funding for a particular project, and the partner (the mainstream Telco) which is a commercial entity. The partnership between the three suggests that each of them has adopted a form of what Billis (2010) would refer to as intra-sectoral hybridity, as they interact across the three sectors. Hybridity brings benefits, including closer working relationships and the ability to share knowledge and experience. It 
can also lead to issues and problems as boundaries become blurred; these problems can be compounded when the hybridity includes all three sectors. In this project, the potential for conflict existed because of this inter-sectoral hybridity, with a particular focus on the role of the not-for-profit and the consequences of setting up a social enterprise (itself a telco), the expectations of the government seed funder and the commercial arrangements established through the mainstream telecommunication company.

There is an extensive literature on NPO government relations, with one stream stressing the importance of partnership in a complex, neo-liberal environment, and the other criticising NPOs for actions that bring both the government and the market into the space of civil society. Taking a wellrehearsed approach, the relationship between the NPO and the government could be seen to have elements of the charity relationship, identified by Furneaux and Ryan (2014), where the government provided seed funding and the NPO provided the service according to its values and ideology. Equally, the relationship could be seen as one of cooperation, where government values align with those of the NPO and the objectives of the two organisations are similar. The project in itself reinforced the relationships between the NPO and government in their mutual support of providing disability services in line with State and Commonwealth policy. However, as this policy was moving towards a marketisation of the disability sector, there was very much a pressure on the NPO to be successful with the social enterprise, signing up participants in the project and other people with disability to the fee-based service, as this would generate another income stream in a policy environment with decreasing government support (Mason \& Brown, 2014). Hence, it could be argued that the NPO government relationship took precedence over the NPO client relationship, as there was a pressure to demonstrate 'success' on multiple levels.

Yet, another layer of potential conflict was introduced when the NPO established a social enterprise as a separate named entity for the implementation of this program and launched it as a business. The relationships between the NPO, the government and the newly established Telco imply a set of relationships for the clients of the NPO with each of the organisations. The establishment of the social enterprise created a triple relationship for participants in the program in stages 1 and 2: they were at 
one and the same time clients of the NPO and customers of the social enterprise as well as being citizens of the government funding the project and recipients of government support. Literature on hybridity tends to focus on NPOs, without consideration for the impact of these potentially blurred roles on their clients. From the client's perspective, they could be regarded as being lured into the relationship with the telco operating as a social enterprise as the program was provided at no cost for its duration. On the completion of the program the individuals were faced with a choice of becoming customers and maintaining their increased dignity, independence and citizenship that technology had provided (in the case of adopters) or not being able to continue with this increased level of citizenship due to the commercial customer relationship of $\$ 40$ per month.

At the macro or societal level of accessibility, a further issue was that the study occurred at a time of major social policy change in Australia, where disability service provision was affected by the introduction of the NDIS. As noted, under this policy change, the relationship between the government, service providers and people with disability is changed fundamentally. The citizen with a disability, who received services directly or indirectly from the NPO or government, is replaced by the customer, who makes economic decisions on the best way to spend the money provided by the government to support them, their families and carers, as they lead what the government refers to as 'an ordinary life'. Confirming this identity as a consumer is the government's description of the 'marketplace', where the person with a disability can maximise 'choice and control' to achieve 'increased social and economic participation'. This policy change added significantly to the philosophical questions about the relationships of participants in the study to the NPO, the social enterprise Telco and the government and to the issues around adherence to social conventions.

At the time of the program initiative, there was a great deal of conjecture as to how the NDIS would work and whetherit could be used to pay for the ongoing contracts with the social enterprise. This uncertainty highlighted the potentially unintended conflicts arising from policy decisions in the minds of some participants and their significant other, where an assistive technology, intended to enhance opportunities for social inclusion and disability citizenship, was perhaps excluded from the scope of a funding scheme intended to increase the choices of people with disability. 


\section{Limitations}

Extrapolating and validating the results of this study to the wider digital economy (macro level) from a small number of participants at the micro level has been a challenge in this paper and it is acknowledged as a limitation. A further limitation arises from the passage of time. Since the end of the study period, the telco established as a social enterprise has been bought from the NPO and become a proprietary limited company, now able to seek equity shareholders willing to invest in the company. It still operates as a social enterprise, but is no longer a program of the NPO. This has implications for studies of hybridity. At the time of the study, an NPO was moving into relatively uncharted territory in order to meet the needs of people with disability for an increased level of social citizenship. In the process of working through effective ways to achieve this, boundaries were blurred and potential conflicts emerged. At the time of writing, there is no longer a blurring of boundaries. What began as a fee-for-service model of social enterprise, with its potential for confusion of roles, has evolved into a service subsidisation model of social enterprise, where the profits from services provided to other customers are used to support the provision of services to customers with disability. Further, the introduction of the NDIS and experience with its operation has removed anxieties about the potential loss of personal and social capital for individuals with disability with high support needs.

\section{Conclusion}

In concluding, there is little doubt that 'Inequalities in using the internet (second level) mirror social inequalities and tend to affect quality of life and opportunities to undertake professional and cultural activities in a wide range of fields (third level)' (Ragnedda, 2017 pp 56-57). This research has shown that for the group involved there was not a single outcome but outcomes relatively evenly split between those who found greatest advantage and were evangelistic towards the technology, those who found the technology useful but without a great deal of competitive advantage over standard Telco offerings, and those for whom the package either did not meet their expectations because of their 
familiarity with mobile technologies or who were uninterested or blocked from access to the technology because of the attitudes of the significant others in their lives.

However, this research has shown that for those that have had their horizons expanded through smart phone technology, the supportive call centre and other factors, their disability citizenship was also expanded across many areas of life. Without these digital skills then they could not be included socially or economically.

The research indicated that for a number of participants, the mobile technologies and training provided greater independence and autonomy away from their service providers and significant others. For some participants, engagement in the program gave them their first opportunity in their lives to undertake activities in their local communities on their own rather than always being in the company of others. This freedom extended to countless activities such as socialising with family and friends, shopping, banking, playing games, taking and sharing photos, catching public transport and for some working independently. People were empowered people to try new activities and even to risk failure as they knew help was only a phone call away. In essence, the technology platform and the associated training and customisation introduced them to the benefits of active citizenship that until that point had been denied. The digital divide caused by the lack of access to the technology effectively reduced their digital capital, hence limiting social capital and their relative position within their communities. What this study reinforces is that in every sense digital citizenship is interrelated in almost every way with social participation and without access to the former then access to the latter is not possible.

At the same time, the multiple relationships between the participants and the organisations involved in this program impinge on the notion of active citizenship and can be seen, even through the lens of disability citizenship, to turn the individual from an active citizen to a client and a consumer. The consequences of NPOs embracing social entrepreneurship, especially in the context of services providing assistive technologies to people with disability aimed at increasing their levels of disability citizenship, need further investigation, in the light of the findings from this study. 


\section{References}

Australian Bureau of Statistics. (2012). Disability, Ageing and Carers, Australia: Summary of Findings, 2012 (Cat No. 4430.0) Retrieved from http://www.abs.gov.au/ausstats/abs@.nsf/mf/4430.0

Australian Communication and Media Authority. (2013). Communications report 2011-12 series, Report 3-Smartphones and tablets Take-up and use in Australia. Retrieved from http://www.slideshare.net/acmaSlideShare/acma-communications-report-201112-seriesreport-3-smartphones-and-tablets

Baker, A. (2012). The New Leviathan: A National Disability Insurance Scheme. The Centre For Independent Studies Policy Monograph 131. Retrieved from https://www.cis.org.au/images/stories/policy-monographs/pm-131.pdf

Barnes, C., Mercer, G., \& Shakespeare, T. (2010). Exploring Disability: A Sociological Introduction ( $2^{\text {nd }}$ ed.) Cambridge: Polity Press.

Billis, D. (Ed.). (2010). Hybrid organisations and the third sector: Challenges for practice,theory and policy. Palgrave McMillan.

Buckmaster, L. and Thomas, M. (2009). Social inclusion and social citizenship towards a truly inclusive society. Parliament of Australia. Research Paper no. 08 2009-10. Retrieved from: https://www.aph.gov.au/About_Parliament/Parliamentary_Departments/Parliamentary_Librar y/pubs/rp/rp0910/10rp08\#_Toc244315401

Commonwealth Government. (2013). National Disability Insurance Scheme - Our History. Retrieved from http://www.ndis.gov.au/about-us/our-history

Cumming, T. M., Strnadová, I., Knox, M., \& Parmenter, T. (2014). Mobile technology in inclusive research: Tools of empowerment. Disability \& Society, 29(7), 999-1012.

Dacin, P. A., Dacin, M. T., \& Matear, M. (2010). Social Entrepreneurship: Why We Don't Need a New Theory and How We Move Forward From Here. Academy of Management Perspectives, 24(3), $37-57$ 
Darcy, S., Green, J., \& Maxwell, H. (2017). I've got a mobile phone too! Hard and soft assistive technology customization and supportive call centres for people with disability. Disability and Rehabilitation: Assistive Technology, 12(4), 341-351.

Darcy, S., Maxwell, H., \& Green, J. (2016). Disability citizenship and independence through mobile technology? A study exploring adoption and use of a mobile technology platform. Disability \& Society, 31(4), 497-519.

Dawans, V., Alter, K., \& Miller, L. (2009). The four lenses strategic framework: Toward an integrated social enterprise methodology. Virtue Ventures LCC. Disponivel em_ $<$ http://www. virtueventures. com/files/fourlenses. pdf.

Dervin, B. (1973). Information needs of urban residents: A conceptual context. in Warner, E. et al. Information Needs of Urban Residents. Final Report. Regional Planning Council, Baltimore, Md.; Westat Research, Inc., Rockville, Md. https://files.eric.ed.gov/fulltext/ED088464.pdf

DiMaggio, P. \& Hargittai, E. (2001). From the 'digital divide' to `digital inequality': Studying Internet use as penetration increases. Working Paper \#15. Center for Arts and Cultural Policy Studies, Princeton University. https://www.princeton.edu/ artspol/workpap/WP15\%20\%20DiMaggio\%2BHargittai.pdf

Ellis, K., \& Kent, M. (2011). Disability and new media. New York:_Routledge.

Friesen, E. L., Theodoros, D., \& Russell, T. G. (2015). Usability-for-one. Work, 52(1), 211-213.

Furneaux, C., \& Ryan, N. (2014). Modelling NPO-government relations: Australian case studies. Public Management Review, 16(8), 1113-1140.

Glaser, B. G., \& Strauss, A. L. (1967). The discovery of grounded theory. London: Weidenfield \& Nicolson.

Goggin, G., \& Newell, C. (2003). Digital disability: The social construction of disability in new media: Rowman \& Littlefield.

Gonzales, A. (2016). The contemporary US digital divide: from initial access to technology maintenance. Information, Communication \& Society, 19(2), 234-248.

Harris, J. (2010). The use, role and application of advanced technology in the lives of disabled people in the UK. Disability \& Society, 25(4), 427-439. 
International Telecommunications Union \& G3ict (2012). Making mobile phones and services accessible for persons with disabilities. Geneva: ITU. Retrieved from: https://www.itu.int/en/ITU-D/Digital-Inclusion/Persons-withDisabilities/Documents/Making\%20Mobile-English.pdf

Khorshed, A., \& Sophia, I. (2015). The digital divide and social inclusion among refugee migrants: A case in regional Australia. Information Technology \& People, 28(2), 344-365. doi:10.1108/ITP-04-2014-0083

Leadbetter, C. 1997. The rise of social entrepreneurship. Demos, London.

Lord, J., \& Hutchison, P. (2003). Individualised support and funding: building blocks for capacity building and inclusion. Disability \& Society, 18(1), 71-86.

Macdonald, S. J., \& Clayton, J. (2012). Back to the future, disability and the digital divide. Disability \& Society, 28(5), 702-718.

Marshall, T H. (1965). Class, Citizenship and Social Development, New York, Harper and Row.

Mason, C., \& Brown, R. (2014). Entrepreneurial ecosystems and growth oriented entrepreneurship. Final Report to OECD, Paris 30(1), 77-102

Oliver, M. (1996). Understanding disability: From theory to practice. New York: St Martin's Press.

Ragnedda, M. (2017). The third digital divide: a Weberian approach to digital inequalities. Abingdon, UK: Routledge.

Reindal, S. M. (2010). Redefining disability: a rejoinder to a critique. Etikk i praksis-Nordic Journal of Applied Ethics, 4(1), 125-135.

Scherer, M. J. (2002). The change in emphasis from people to person: introduction to the special issue on Assistive Technology. Disability and rehabilitation, 24(1-3), 1-4.

Swain, J., French, S., \& Cameron, C. (2003). Controversial issues in a disabling society. Maidenhead, Berks.: Open University Press.

Thomas, C. (2004). How is disability understood? An examination of sociological approaches. Disability \& Society, 19(6), 569-583. 
United Nations. (2006). Convention on the Rights of Persons with Disabilities. Retrieved from http://www.un.org/disabilities/convention/conventionfull.shtml

van Dijk, J. (1999). The Network Society, Social aspects of the new media. Thousand Oaks: Sage Publications

Vehmas, S., \& Mäkelä, P. (2009). The ontology of disability and impairment: a discussion of the natural and social features. In K. Kristiansen, S. Vehmas, \& T. Shakespeare (Eds.), Arguing about Disability: Philosophical Perspectives (pp. 42-56). New York: Routledge.

Warschauer, M. (2003). Technology and social inclusion: Rethinking the digital divide. Cambridge, MA: MIT Press.

Wilson, E. J. (2006). The information revolution and developing countries. Cambridge, MA: MIT Press.

World Health Organization. (2001). International Classification of Functioning, Disability and Health: ICF. World Health Organization.

Zahra, S. A. Gedajlovic, E., Neubaum, D., \& Shulman, J. (2009). A typology of social entrepreneurs: motives, search processes and ethicalchallenges. Journal of Business Venturing (24), 519$532,-$. 